\title{
ADOPTION OF AUTOMATIC IDENTIFICATION SYSTEMS BY GROCERY RETAILERS IN THE JOHANNESBURG AREA
}

\author{
CHRISTOPHER CHARLES DARLINGTON* \\ BORIS URBAN** \\ *Milpark Business School \\ ${ }^{\star *}$ Graduate School of Business Administration, University of the Witwatersrand \\ Boris.urban@wits.ac.za
}

\begin{abstract}
Retailers not only need the right data capture technology to meet the requirements of their applications, they must also decide on what the optimum technology is from the different symbologies that have been developed over the years. Automatic identification systems (AIS) are a priority to decision makers as they attempt to obtain the best blend of equipment to ensure greater loss prevention and higher reliability in data capture. However there is a risk of having too simplistic a view of adopting AIS, since no one solution is applicable across an industry or business model. This problem is addressed through an exploratory, descriptive study, where the nature and value of AIS adoption by grocery retailers in the Johannesburg area is interrogated. Mixed empirical results indicate that, as retailers adopt AIS in order to improve their supply chain management systems, different types of applications are associated with various constraints and opportunities. Overall this study is in line with previous research that supports the notion that supply chain decisions are of a strategic nature even though efficient management of information is a day-to-day business operational decision.
\end{abstract}

\section{INTRODUCTION}

In today's business environment remaining competitive and adopting innovative approaches to supply chain management is critical for success (Bredell \& Walters, 2007). Productivity is a key performance indicator for any industry and it is becoming widely accepted that barcode data collection technology is one of the best productivity investments a company can make. Today, companies not only need the right data capture technology to meet the requirements of their applications, they must first decide on what the optimum technology is for their business from the different symbologies that have been developed (Christensen, 1997; Datalogic, 2009).

The emergence of automatic identification systems (AIS), including barcodes and the related printers, scanners and software, has significantly increased the speed, efficiency and accuracy of data collection and entry. Early applications of barcode scanning, which included retail 
point-of-sale (POS), item tracking and inventory control, have been expanded to include more advanced applications such as time and attendance, work-in-process, quality control, sorting, order entry, document tracking, shipping and receiving, and controlling access to secure areas (Burke, 1984; Datalogic, 2004).

Barcode data-collection technology is an effective way to improve the bottom line and meet the competitive challenges organisations face every day (Burke, 1984; Darlington, 2009). When combined with data-collection technology, barcodes provide a rapid, accurate and efficient means to collect, process, transmit, record and manage data in a variety of industries. Retail, package delivery, warehousing and distribution, manufacturing, healthcare and point-of-service applications can all benefit from the use of automatic identification, such as bar coding (King, 2010).

While barcodes are considered a mature technology, the historical focus of barcodes has concentrated on identification of an object type. There are two standard types of barcodes that you would typically come across: the 1-dimensional, such as the EAN 128, and the 2-dimensional, such as the Datamatrix (Crump, 2011). The adoption of the new GS1 barcodes, 2-dimensional codes and the EAN/UPC barcodes has unlocked enormous data-capturing abilities for retailers and other industries. Barcode technology continues to perform an essential role in inventory control and distribution, particularly in the consumer product market sector, but can be found in use from car manufacture to library stock control. Barcodes require close scanning with an optical reader, much like the laser scanning readers found at most supermarket checkouts (Burke, 1984).

Automatic identification, such as barcoding, and the continuous development of computer technology, have given industry improved control systems for managing transportation and production processes, as well as warehouses and retail store management (Burke, 1984; Datalogic, 2004). The continuous development of computer technology has measurably increased productivity by linking production, warehousing, distribution, sales, and service to management information systems on a batch or real-time basis (Christensen, 1997; Urban \& Mangisi, 2008).

AIS are a priority to decision makers in retail as they attempt to obtain the best blend of equipment to ensure greater loss prevention and higher reliability in data capture. Key entry is often used as the fall-back method. If the main (and more automatic) method of data capture fails to any extent, then the quality of the entire database may depend on the reliability features built into the key entry procedures (Atkinson, 2010). In many cases, efforts go towards the main systems design at the expense of the back-up key entry system. Yet, this can often prove to be the weak link in the chain (Datalogic Scanning, 2007; Yu, 2005). 


\section{Problem statement}

Currently in the retail industry, several retail application systems that worked well 10 or 20 years ago are no longer robust enough to meet today's business needs. An essential issue which all retailers must at some point decide upon is whether they need to capture detailed sales information at merchandise line item level. This is a perennial problem throughout the retail supply chain. Indeed there is a risk of having too simplistic a view of the options open to adopting AIS, since no one solution is applicable across an industry or business model (Joshi, 2009). This problem is addressed through an exploratory, descriptive study, where the nature and value of AIS adoption by grocery retailers in the Johannesburg area is interrogated.

There are enormous advantages to be gained from the collection of barcode data, but equally there may be massive problems (and costs) associated with such an operation. Issues concerning implementation of AIS are of great concern to retailers, as are the potential resistors to such changes (Bitner, Gremler \& Zeithaml, 2006; Hum \& Marciano, 2010). Many projects fail to deliver promised benefits because management did not conduct adequate project post-mortems, neglected to audit system usage, did not examine information flows, and failed to revisit the project's justification (Walker, 2010). These issues are surveyed and further analysed in this study.

\section{Purpose of the study}

The aim of this research is to determine the nature and perceived value associated with the adoption of AIS in the grocery retail supply chain industry. To address this aim the following aspects are investigated:

- the drivers leading to the adoption and implementation of AIS

- the types and levels of adoption of AIS and similar systems

- the value of AIS in supply chain management

- the challenges and resistance to change that retail organisations must overcome in implementing and upgrading AIS

- the proposed measures to support the adoption of AIS

Correspondingly, the objectives of this study are to provide a better understanding of the above-mentioned issues and gain insights through empirical investigations, which hopefully will allow for solid theory to emerge. A practical objective of the study is to provide guidance to retailers on the types, benefits and implementation issues associated with adopting AIS. 


\section{LITERATURE REVIEW}

The past ten years have seen a period of profound change in the retail industry, and information technology has affected both operational and strategic aspects of supply chain management. These changes have affected the most casual customer interactions to the reconfiguring of entire complex supply chains (Das Neves, Fenn \& Sulcas, 2004). Many retailers have been able to take advantage of the worldwide demographic shifts and falling trade barriers that have opened new markets and created low-cost sourcing opportunities (Phillips, 2009).

Recognising these transformations in information technology, several factors have been identified that are currently shaping the retail supply chain industry, including (Dos Santos, 2010; National Academies, 2005):

- globalisation of communications and commerce

- macro-environmental trends

- advanced integrated information infrastructure

- modernisation of processes, vertical disaggregation and outsourcing; and

- expanded value chains

From an information technology perspective, supply chain management involves efficient inventory management through a systematic approach applied across supply chain partners. Information technology focuses on the need to look at value delivery to the customer. The ultimate goal of supply chain management is to bring efficiency in procurement and meet customer's demand effectively. Moreover there is a need to plan, manage and optimise inventory and capacity in a company's operations and communicate the planning and inventory information between the various levels of suppliers and customers (Joshi, 2009; Conceivious, 2010). This is particularly relevant in retail industry, as the value flows from the vendor to the customer through the retailer.

Experts agree that supply chain decisions are of a strategic nature even though efficient management of inventory is a day-to-day business operational decision (Erasmus, 2002). Transaction processing systems are an important example of operations support systems that record and process data resulting from business transactions. They process transactions in two basic ways. In batch processing, transactions data are accumulated over a period of time and processed periodically. In real-time (or online) processing, data are processed immediately after a transaction occurs (Joshi, 2009).

Focusing on operations support systems, enterprise resource planning (ERP) systems integrate diverse business processes and provide consistent reporting; however, they are also 
difficult to implement and as such pose challenges. They require not only large investment in technologies, but force fundamental changes in the way the business operates. The ERP system requires complex software and large investments of time, money and expertise (Urban \& Mangisi, 2008; Joshi, 2009). One of the necessary information technologies behind the ERP system is the automatic identification infrastructure that allows processes and transactions to be traced and controlled in order to gather enough information to be processed at a higher end.

In order to automate the retail operation, certain systems are required to mark the products in a manner that are suitable for machine reading. This facilitates automation of data capturing and its subsequent use in the information systems to help operations, management and planning (Joshi, 2009). Automated data capturing involves product-marking systems that are designed to uniquely identify product at any level. Optical identification represents approximately $75 \%$ of all identification systems currently in use. Barcoding is the form of printed data which can be easily and automatically read by means of a reading device. Barcode applications can be found in all fields of industry, retail, the public sector and everyday life (Datalogic, 2004). The technology was created in the 1940s and has maintained its status as the legend of automated data collection. Barcode technology was designed to make checking out of items in grocery stores automatic. It offers speed and reliability in collecting data, and can scan countless items with precision. The latest innovation in barcode formats has established an error rate generation of less than 1:1 000000 (Walker, 2009).

Automatic identification or 'auto-ID' encompasses the automatic recognition, decoding, processing, transmission and recording of data, most commonly through the printing and reading of information encoded in barcodes. Barcodes allow for rapid, simple and accurate reading and transmission of data for items that need to be tracked or managed. Barcode labels are easily affixed or can be directly printed onto a wide range of items for identification (Burke, 1984; Christensen, 1997).

Early applications of barcode scanning, which included retail POS, item tracking and inventory control, have been expanded to include more advanced applications such as time-andattendance applications, work-in-process, quality control, sorting, order entry, document tracking, shipping and receiving, and controlling access to secure areas (Datalogic, 2009). Perhaps the simplest example of barcoding is at the supermarket checkout counter. If product manufacturers and supermarkets did not use barcodes, cashiers would have to manually read a code from each item or a list, and key the code into the register. If the cashier misread or mistyped, he or she would have to try again. This is, of course, what was done before barcode systems were implemented, and it is easy to recognise the efficiencies gained by automating that process. Beyond efficient data collection, AIS perform tasks that would be much more difficult to accomplish manually. Magnetic ink character recognition 
(MICR), for instance, allows merchants to detect whether a customer is attempting to pass a counterfeit cheque.

Various kinds of product-marking systems are available to provide an optimal fit in a supply chain, namely: price labelling, magnetic stripe, barcode technology, radio frequency identification and shelf-edge labelling. Of these five most popular forms of automatic identification techniques, barcoding is the most cost effective and widely used system globally (Dennison, 2010). Nonetheless each product-marking system has limitations and as the technology progresses, it will ultimately lead to more frequent system revamps to accommodate more compatible, efficient systems as well as the continuous costs to implementation. Technology helps retail supply chains to manage their inventory and to increase their sales performance through online sales. Moreover technology assists supply chains to integrate demand management and to enhance collaborative planning, forecasting and replenishment (CPFR) (Atkinson, 2010).

Barcodes are widely used to implement automatic identification and data capture systems to improve the speed and accuracy of computer data entry. Fast and accurate data entry and retrieval is the core of barcode technology. Barcodes play a major role in retail automation, aiding monitoring of stocks in the entire supply chain (warehouses, distribution and retail stores). Improved inventory management by reducing inventory in transit and dead stocks is the leading motivation driving the use of barcode in the retail industry (Baxter, 2010). Other major benefits of barcodes include:

- Accurate capture of data ensures proper maintenance of records and transactions. Scanning at the POS and the goods receiving will eliminate the source of human error.

- Reduction of workforce costs and better management control over the operations results from barcodes eliminating the need to have manual pricing and reducing the need for manual stocktaking.

- Barcode technology helps in calculations of the checkout productivity at stock and sales levels.

- It ensures fast transaction completion at POS and warehouse.

- It leads to decreased checkout time at the POS, thus giving rise to higher customer satisfaction. Again, there will be fewer cashier errors, and customers will automatically get an itemised receipt.

- It will ensure faster customer throughput at high-volumes stores. It will automatically generate price and itemised billing. It helps in implementing productivity control.

- As satisfaction breeds loyalty, barcoding can help the promotion of customer loyalty programmes.

- The benefits to management will likewise include provision of faster access to raw data, i.e. on a real-time basis leading to faster management reports and more effective decisions. 
- Barcoding gives management confidence about the data which results in better operations control, management control and planning (Datalogic Scanning, 2007; Joshi, 2009).

An innovation to bar coding is electronic shelf labels which are electronic display panels on retail store shelves. These panels display product description, pricing or any promotional schemes offered by the retailer. The current pricing and promotion labels on the shelf still have to be attached manually and this could result in human errors. Pre-printed barcodes are also used where very durable, high quality labels are necessary to withstand the environment (such as on printed circuit boards), or where high-volume packaging or labelling is done.

Barcode systems can use several symbologies. A symbology is equivalent to a language. Even though each symbology has strengths and weaknesses, several symbologies persist for historical or commercial reasons, while others have definitive technical advantages. All symbologies have some limitations on the number and type of characters that can be encoded numeric or alpha numeric. UPC-A (universal product code) is the most limiting (Datalogic Scanning, 2007). It is a numeric-only barcode that must consist of 12 digits. Furthermore, the value of these digits is determined by standards managed by the GS1 Council in South Africa, and by EAN International. Code 128 is the most flexible, with the full (128-character) ASCII set available (Datalogic Scanning, 2007). The new barcode symbols are said to be made of linear barcodes which are readable by laser-based POS terminals and handheld scanners. These symbols are designed to expand the utility of GS1 barcode labelling for POS and general use (Moore, 2009). Another new application is the new reduced space symbology (RSS) coupon barcode. Experts advise that retailers need to develop a comprehensive plan and manage company-wide RSS implementation. Included should be identifying POS and systems upgrade requirements such as hardware, software, training and management, as well as cost implications from suppliers such as POS vendors and clearinghouses (Anonymous, 2006).

Radio frequency identification (RFID) technology is the new-generation automatic identification and data-capture technology that uses radio or wireless communication to uniquely identify and transmit data relating to an item, object or individual. RFID has sought to replace the barcode system for tracking products. RFID is helping retailers around the world improve customer satisfaction and increase sales. The technology is transforming the retail industry by offering retailers real-time visibility into inventory and product movement to improve store productivity and loss prevention. Many of the world's largest retailers have mandated RFID tagging. This move affects more than 200000 manufacturers and suppliers, driving the worldwide market for hardware and software to support RFID (Reese, 2010). By acknowledging that technology is transforming the retail industry by improving store productivity and loss prevention, retailers need to start planning and budgeting for the changes AIS will inevitably bring about. 


\section{RESEARCH STRATEGY}

\section{Research approach}

The design of the study was largely exploratory and cross-sectional, where quantitative data was collected by means of structured questionnaires. Since existing research has not yielded generalisable knowledge on AIS implementation issues it was posited that a crosssectional, survey-based descriptive study, generating empirical results, would add to the body of knowledge in this new direction of study. The process of building solid theory begins by describing the phenomena that one wants to understand. Once the phenomena have been thoroughly characterised, the researcher can begin to classify the phenomena into categories to more meaningfully understand the complex array of relationships between them. Consequently, exploratory studies are a valuable means of finding out what is happening and an opportunity to ask questions and assess phenomena where little research exits (Cooper \& Schindler, 2001).

\section{Sampling}

The target population was grocery retailers situated in the greater Johannesburg area and was based on three sub-divisions, namely: convenience retail stores, small-to-medium retail stores, and super retail stores. The sampling frame was based on Nielsen's (2011) grocery universe and the following retailer formats were surveyed:

- Shoprite Checkers supermarket and hyperama type stores

- Pick 'n Pay convenience (franchise), supermarket and hypermarket type stores

- Spar convenience (franchise), and supermarket type stores.

Stratified random sampling was used as it was relatively simple to stratify the sampling frame using the characteristics of retail format and type of technologies used. This ensured a final sample size of 86 respondents, resulting in a $43 \%$ response rate.

\section{Instrument}

A survey was designed to identify the nature of barcode systems and benefits of implementing these systems within a retail supply chain environment. The survey collected descriptive data. The content part of the questionnaire was developed and based on existing conceptualisations of AIS. A structured questionnaire measuring the following was administered over a three-month period: the level of adoption of AIS and similar systems and the capital out-lay and running costs of AIS; the potential value of implementing AIS in the short term as opposed to remaining with a manual system; the short-term competitive advantage of implementing barcode systems compared to other systems within a retail supply chain; the challenges and resistance to change that retail organisations must overcome in implementing and upgrading AIS. 
All items were developed on the basis of the literature review and reflect core themes as gleaned from previous research findings on this topic. Twenty variables were identified in an attempt to assess the level of responsiveness to practices as a result of AIS implementation. Questions were measured on a 1-5 Likert scale where ' 1 ' indicates respondents 'strongly disagree', to ' 5 ' where respondents would 'strongly agree' with the statements.

The survey was solicited electronically with periodic reminder telephone calls. Permission was obtained from the individuals to voluntarily undertake the survey and ethical clearance to contact members was established with the participating institutions. The respondents were middle and senior representatives in the organisations. Each respondent was directly involved in implementing or overseeing automatic identification products within the retail store.

\section{Data analysis}

In order to ensure the instrument had face and content validity, a preliminary analysis via a pilot test was undertaken. This process allowed the researcher to refine the questionnaire design to maximise responses. This procedure ensured that the respondents had no difficulties in answering the questions and there was no problem in recording the data. Based on the exploratory nature of the study, frequencies and descriptive statistics were calculated, which is in line with the objectives of describing the phenomena under scrutiny. Since the study was cross-sectional it is not possible to look at the dynamics of these perceptions nor can the study determine any causal influences, and subsequently only descriptives were calculated.

Due to space limitations only key results are displayed, while other findings are discussed in conjunction with these figures.

\section{DISCUSSION}

A descriptive set of results based on percentage analysis is displayed in Figure 1 which is largely self-explanatory.

Figure 1 shows the data gathered for the sample group with regard to primarily investing in AIS within their organisation. The majority (73.9\%) of the respondents invested in AIS to increase their operational improvements, while only a few of respondents purchased the AIS for industry compliance. This could be due to the supply chain adopting AIS systems to track and trace products throughout the supply chain. 


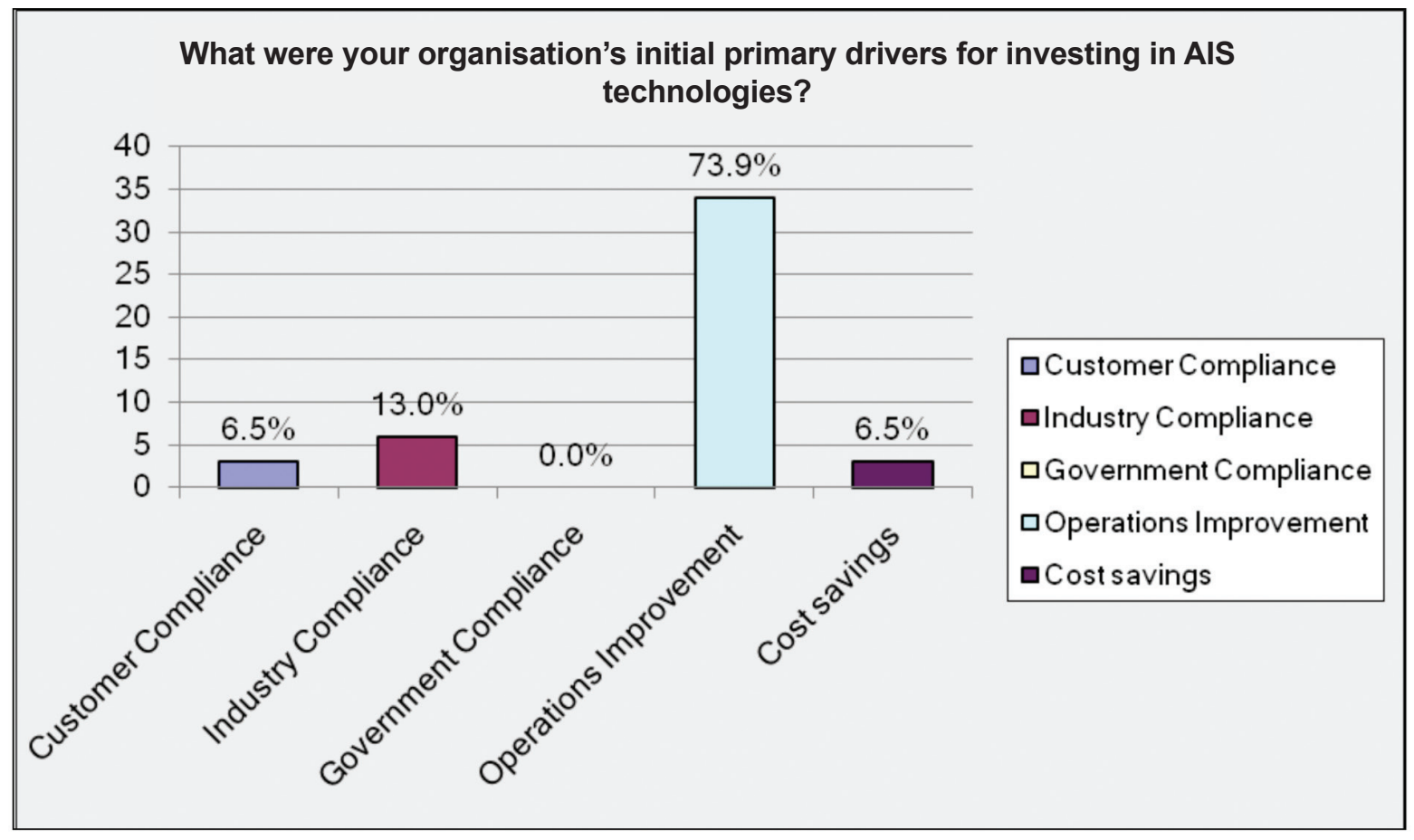

Figure 1: Primary drivers for investing in AIS technologies

Results also indicate that multiple AIS products are used in the retail environment, with the majority of the sample (60.4\%) using handheld barcode scanners. The purchase estimates for AIS products over a three-year period from 2009-2011, indicate that the majority of the purchases for 2009 were in the R250 000-R500 000 region; in 2010 the estimated expense was mostly in the R250 000-R500 000 region; while in 2011, so far, estimated AIS purchases were between R100 000 and R250 000 (not shown).

Figure 2 shows how often an AIS device is replaced within a seven-year period. The most frequently replaced products are the consumables such as the barcode labels and ribbons. However on average the handheld scanners and the mobile computers take four to five years to replace which is a relatively common life-cycle trend (Darlington, 2009). 


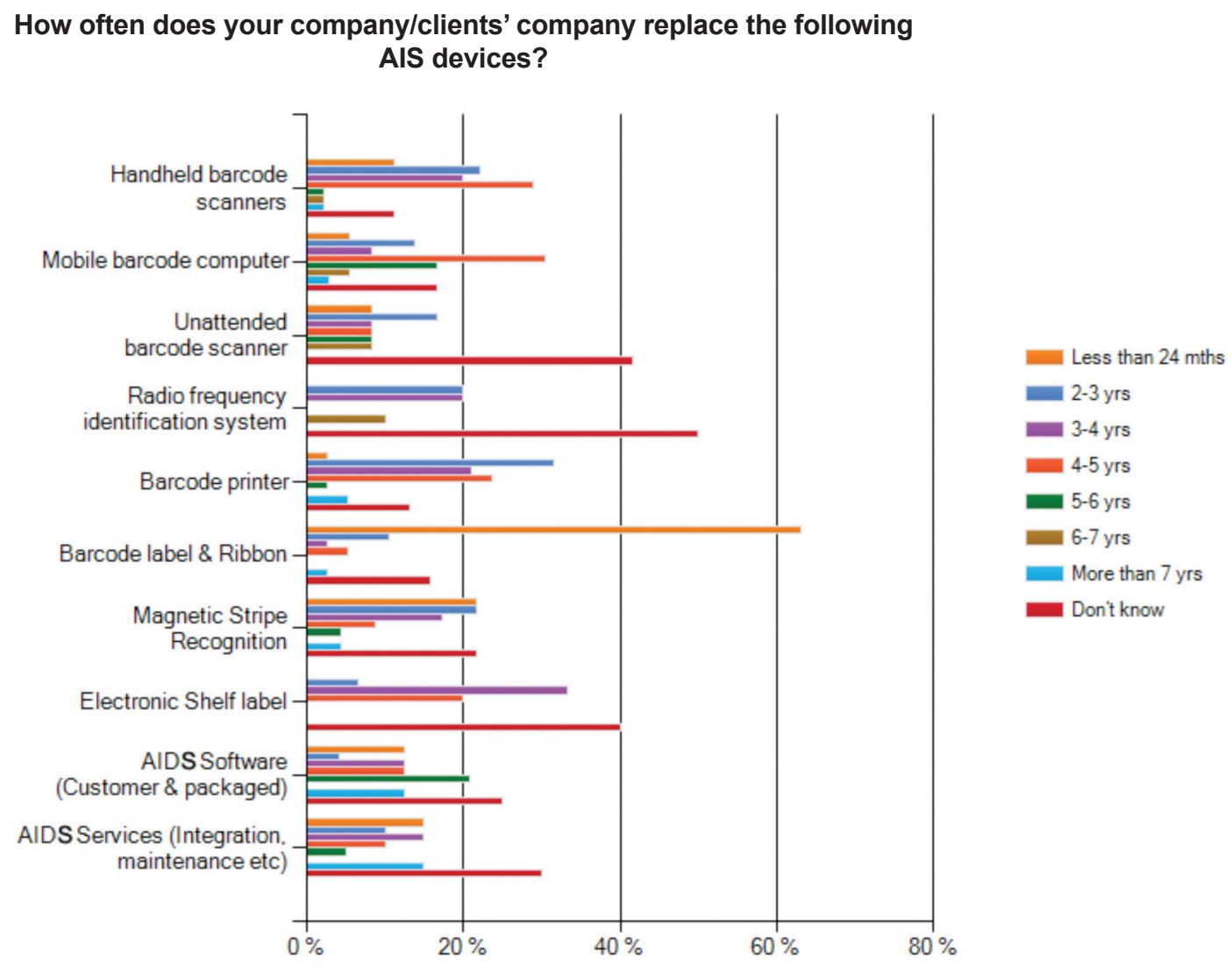

Figure 2: Replacement of AIS devices

Figure 3 shows the number of barcodes that these retailers will print. Generally the more symbologies printed within a retail store environment, the larger the variety of store items and the greater the probability that the GS1 code would be required. GS1 code symbols can carry more data in the same amount of space, or the same quantity of data in less space than EAN/UPC barcodes. While EAN/UPC barcodes will remain useful for product identification, the GS1 code enables expanded barcode implementation by meeting the objective of identifying small items and carrying more information than the current EAN/ UPC barcodes allow (Datalogic Scanning, 2007). 
Approximately how many different bar code symbologies does/will your organisation print?

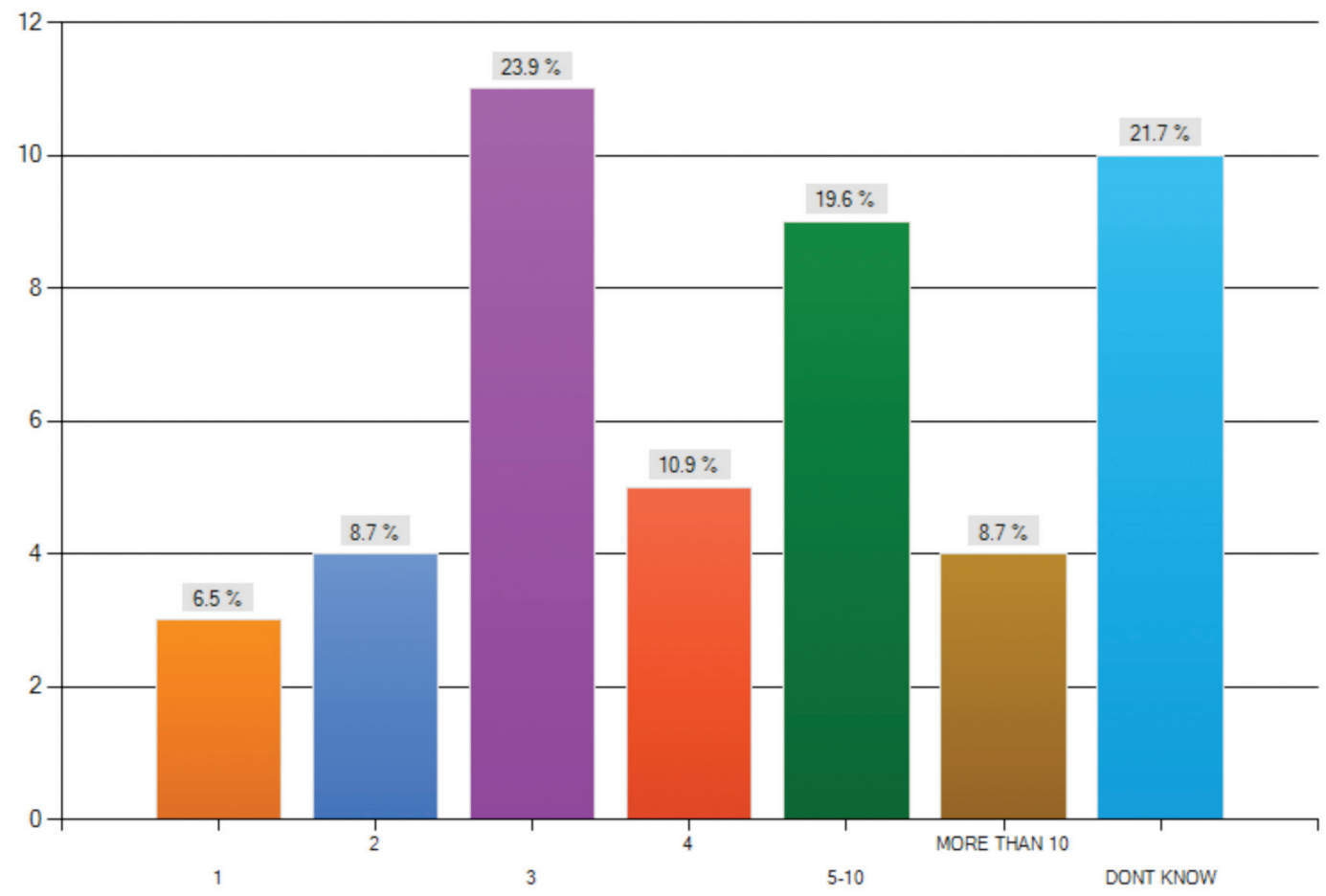

Figure 3: Different barcode symbologies

Further findings reveal that in the adoption rate of new technology to read the GS1 barcoding, $31.1 \%$ of those who have implemented the GS1 barcode required a hardware upgrade. Moreover the adoption of new technology has been costly to implement. Of the respondents who had adopted the GS1 barcode, $21.7 \%$ had indicated that it was extremely costly in the hardware upgrade, while $31.2 \%$ had believed that it was relatively costly to implement new GS1-ready hardware, and $10.9 \%$ of the respondents stated that it was not costly at all to implement (not shown).

Questions were also posed to determine the respondents' perceptions of what measures need to be undertaken in order to improve their supply chain success (multiple answers were encouraged where applicable, see Figure 4). The measure mentioned most frequently is to improve strategic planning in terms of supply chain strategy and operations. A pertinent observation is that $42 \%$ of respondents indicate that they have started implementing e-procurement, while $41 \%$ are already improving their e-procurement system and $18 \%$ were already satisfied. 
Which of the following do you think that your company needs to do in order to manage its supply chain better?

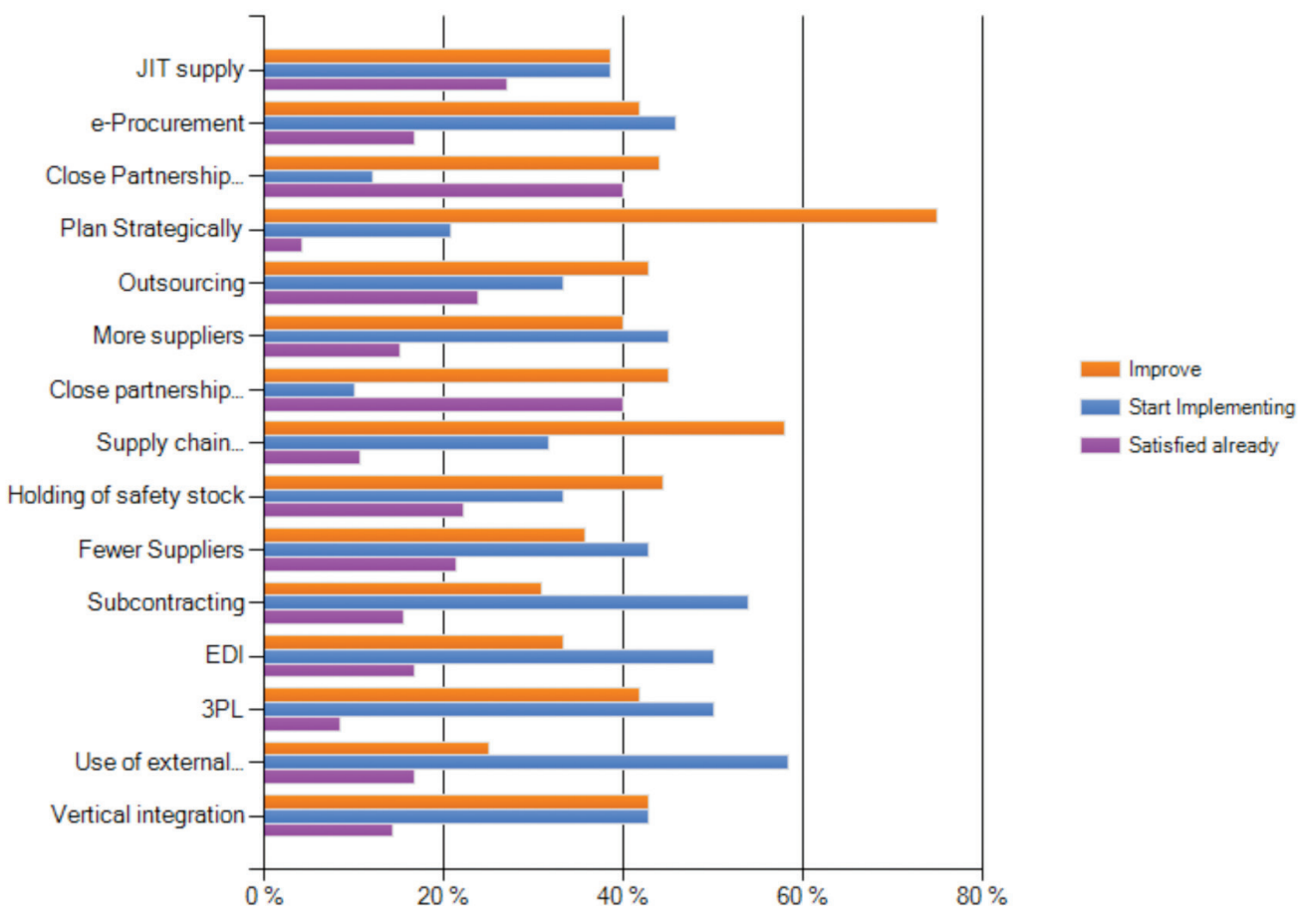

Figure 4: Measures to improve supply chain management

Figure 5 depicts the current AIS that are utilised by the respondents. The question was in list form and multiple answers were encouraged where applicable. Based on the results it seems it is not particularly important whether the AIS used was a customised system or not. In Figure 6 the perceived benefits of these implemented systems is displayed.

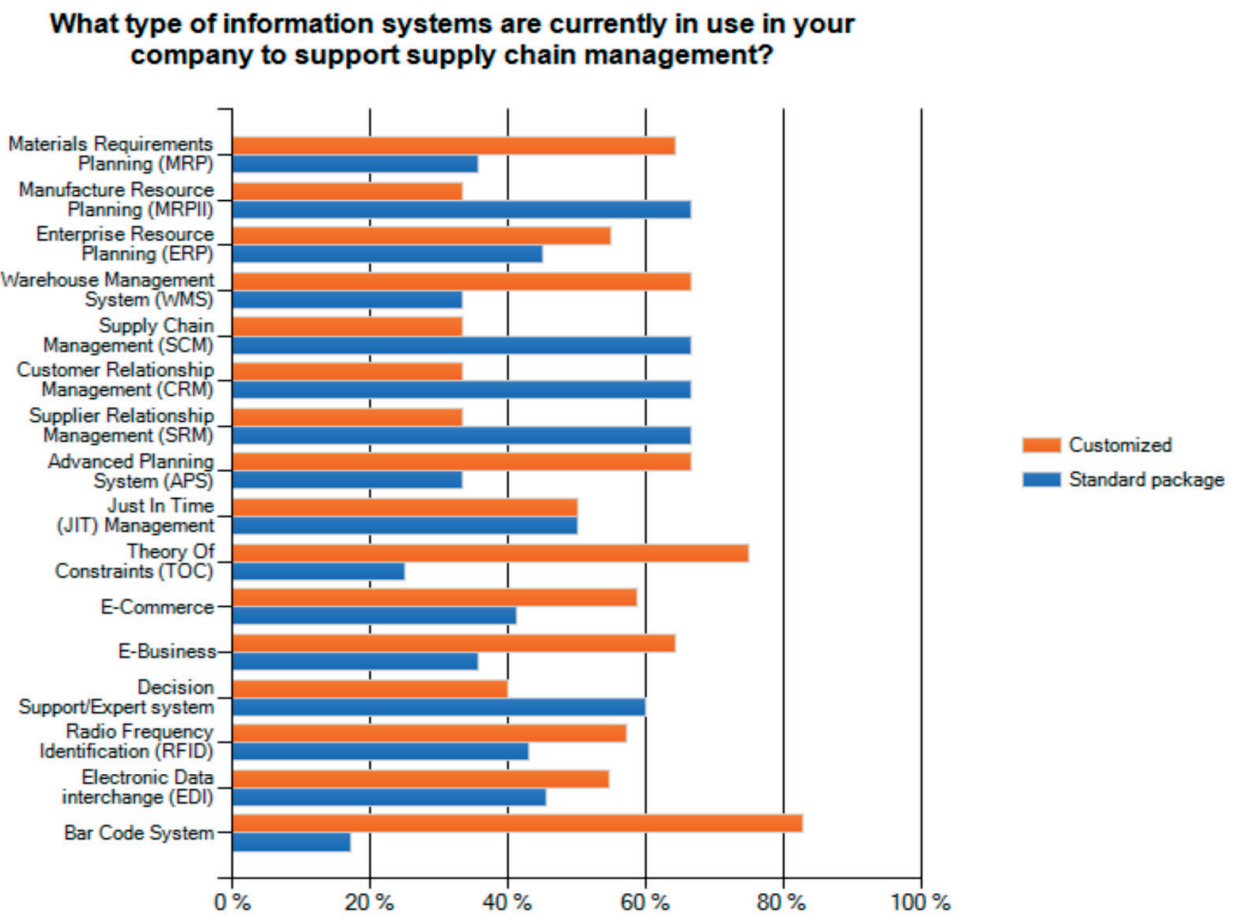

Figure 5: Type of AIS currently in use 


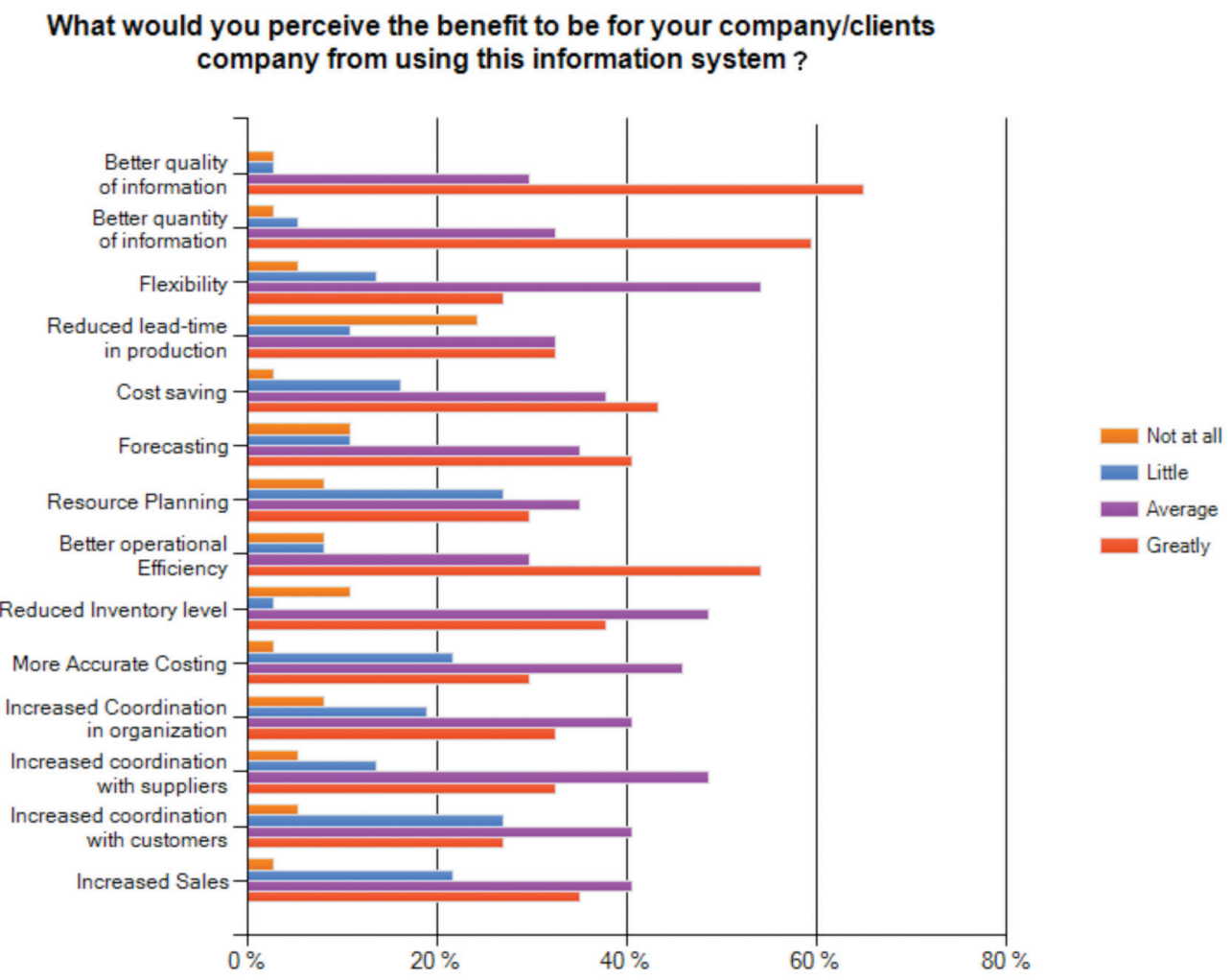

Figure 6: Perceived benefits from adopting AIS in the supply chain

Figure 7 indicates a variety of issues perceived to be problems while adopting AIS in the overall supply chain. The most significant problem observed is the skills shortage with regards to computer literacy and operating competency of the current information systems.

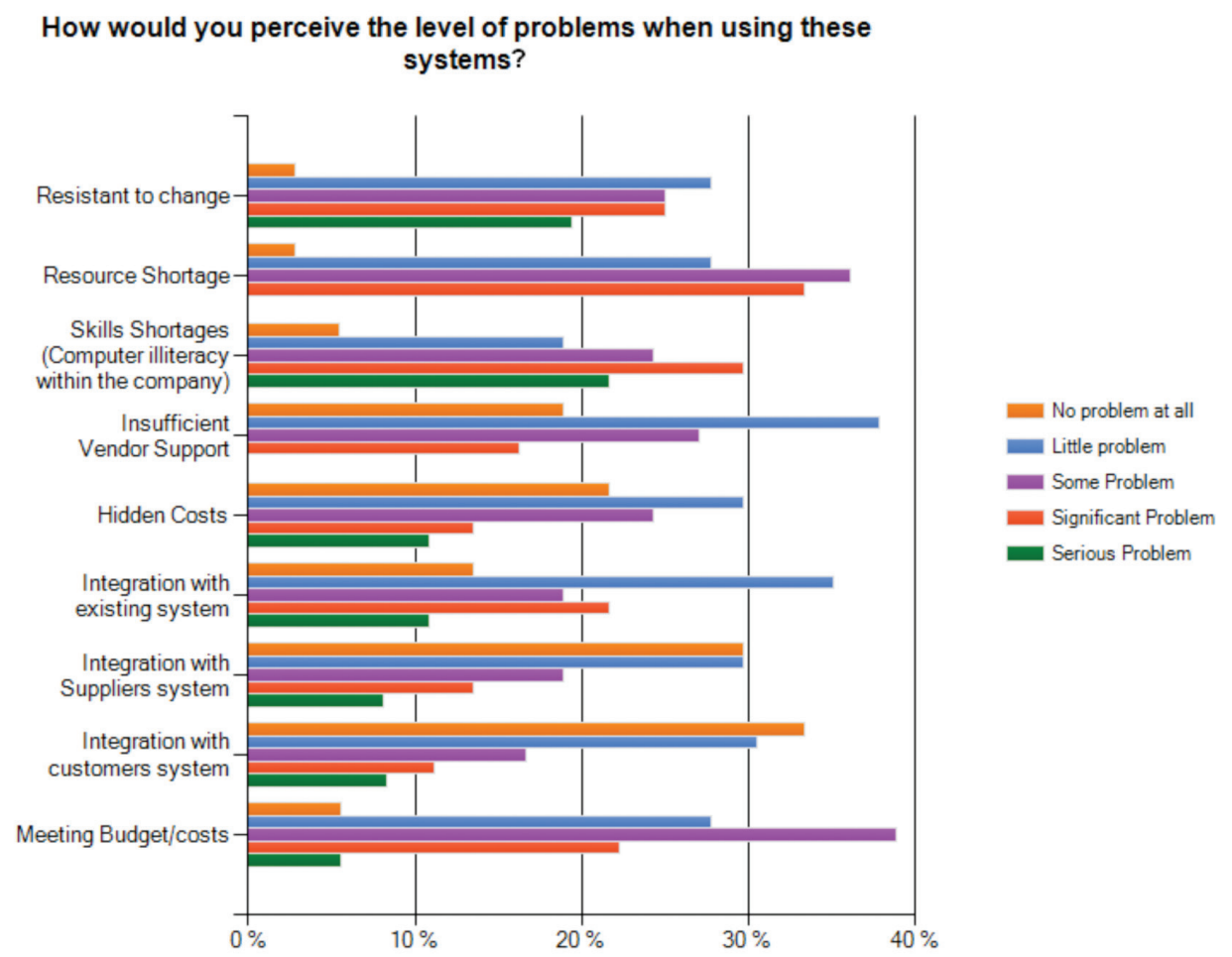

Figure 7: Problems when adopting AIS in the supply chain 
Figure 8 shows the results of measures that are relevant in supporting the adoption of AIS in the overall supply chain system. The most important responses are that more formal education is necessary to successfully improving the information system, as well as a closer co-operation with staff. It is further observed that more funding and financial support is required to improve the information system in the future, as well as a better informational infrastructure and reporting structure.

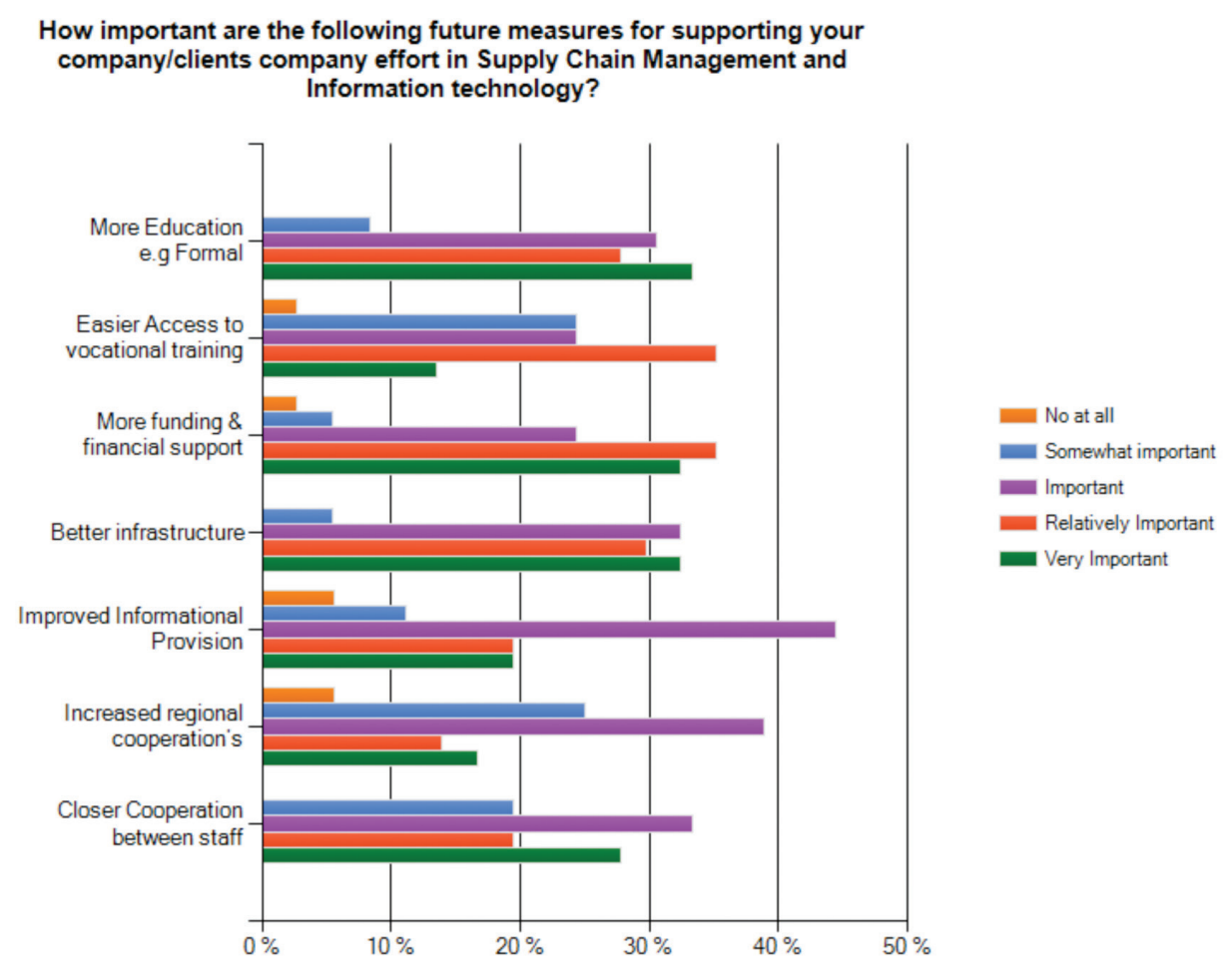

Figure 8: Measures for supporting the adoption of AIS

\section{CONCLUSION}

The empirical evidence emanating from this study has addressed the study objectives, where respondents have reported on: 1) the factors leading to the adoption of AIS implementation; 2) the types, benefits and costs of AIS; 3) the value of AIS in supply chain management; and 4) the measures to support the adoption of AIS. Generally mixed results demonstrate, as retailers adopt AIS in order to improve their supply chain management systems, that this has opened a new passage to more and different types of information technology applications with associated constraints and opportunities. Overall this study is in line with previous research that supports the notion that supply chain decisions are of a strategic nature even though efficient management of information is a day-to-day business operational decision. Not only must obstacles to the adoption of AIS be successfully overcome but as the implementation of AIS typically requires a large investment and entails change in current business processes 
and practices, proper support measures must be put in place. Change is always daunting but if organisations wish to keep up with the fast pace of technology implementations they must be one step ahead of the competition (Brits, 2006).

As supply chain networks become more complex, the need for greater and improved supply chain technology solutions has become critical. Although ERP and SCM solutions have made a significant difference in addressing the needs of retailer information technology needs, these technologies coupled with AIS have enabled the supply chain 'knowledge worker' to innovate, drive cost reductions, improve service and meet customer expectations. AIS also have the potential of tailoring service levels to specific customer segments and the importance of making a supply chain as short, simple and flexible as possible is often recommended (Mercier, Sirkin \& Bratton, 2009).

Existing research confirms that multiple factors require attention and problems arise from adopting new technology systems (Urban \& Mangisi, 2008). Barcode technology is helping retailers around the world improve customer satisfaction and increase sales. The technology is transforming the retail industry by offering retailers real-time visibility into inventory and product movement to improve store productivity and loss prevention (Datalogic Scanning, 2007). By narrowing down the research focus on specific aspects of AIS in the grocery retail environment, insights into the importance of information systems are obtained.

The limitations of this study are typically survey design concerns pertaining to self-serving bias and the cross-sectional nature of the design. Future longitudinal research could be conducted to analyse the evolution and implementation of AIS issues and challenges over a period of time to discern if any similar patterns arise throughout the supply chain industry.

\section{Recommendations}

Multi-channel retail consumer interaction, store traffic and sales are being driven by information systems that are fully integrated with the retailers' strategy. As a result it is suggested that retailers adopt an integrated e-commerce solution, which eliminates the extra effort and expense of maintaining inventory in multiple systems. Much time and money could be saved by using just one system to manage their retail stores, warehouse and e-commerce efforts (Frome, 2010). Retailers are beginning to recognise that e-commerce is becoming more integrated within their traditional business through information system infrastructure. As e-commerce traffic can drive store traffic and vice versa, it is recommended that the retail supply chain take advantage of how it can grow their business by leveraging their channels.

Moreover, with increased information systems and cloud-computing sharing sales and inventory data, it will become more commonplace between suppliers and retailers 
to partner. The real benefits come about when the retailer provides the supplier with information relating to their products' performance in terms of sales, stock, future demand, etc. Cloud-computing and continuously developed information systems will enable many mid-size retailers to start sharing data with their suppliers for the very first time, and enable some of their larger retailers to share and implement these processes with even more of their vendors. Through collaboration with suppliers, retailers are able to use innovation in all areas of business to respond to changes in the macro-environment and obtain a clear competitive advantage in an already saturated market (Dos Santos, 2010).

With an increase in the intricacy and sophistication of products, the needs of retailers are moving beyond identification of product type to unique identification of individual objects by serial number. This represents a significant transition because unique identification introduces a much greater degree of complexity in system management. Retailers are urged to consider that unique identification also offers a number of possibilities that include greater visibility and real-time control of objects located anywhere between the manufacturer and the customer. The full realisation of these capabilities will most certainly revolutionise supply chain management practices. 


\section{REFERENCES}

Anonymous. 2006. Cracking the Code. Retail Merchandiser, 15308154, Nov 46(11):5-6.

Atkinson, W. 2010. Technology trends in the retail supply chain. Supply Chain Management Review. 14(1):49-51.

Baxter, M. 2010. Price checkers and digital signage can provide data to customers. White Paper. Available from: http://www.retailcustomerexperience.com.html (accessed 20 April 2010).

Bitner, J.M., Gremler, D.D. \& Zeithaml, V.A. 2006. Services marketing: integrating customer focus across the firm. 4th Edition. Singapore: McGraw-Hill International.

Bredell, R. \& Walters, J. 2007. Integrate supply chain risk management. Journal of Transport and Supply Chain Management. 1(1):1-17.

Brits, G. 2006. Change is inevitable. South African Farm Practice. 48(1):64.

Burke, H. 1984. Handbook of bar coding systems. New York: Van Nostrand Reinhold Company Ltd.

Christensen, C.M. 1997. The innovator's dilemma: when new technologies cause great firms to fail. Boston: Harvard Business School Press.

Conceivious, H.I.P. 2010. The impact of customer-specific requirements on supply chain management. Journal of Transport and Supply Chain Management. 4(1):57-68.

Cooper, D.R. \& Schindler, P.S. 2001. Business research methods. 7th edition. Singapore: McGraw-Hill.

Crump, N. 2011. Selecting the best data capture device. MHD Supply Chain Solutions. Jul/ Aug 41(4):32-33.

Darlington, G. 2009. DCl scanning. A supply chain perspective. Unpublished paper presented to Christopher Darlington, DCl Scanning Pty Ltd, 30 March 2009.

Das Neves, D., Fenn, D. \& Sulcas, P. 2004. Selection of Enterprise Resource Planning (ERP) systems. South African Journal of Business Management. 35(1):46-52. 
Datalogic Scanning. 2007. All about barcodes. Datalogic Scanning. Available from: http:// www.datalogicscanning.com.html (accessed 21 March 2010).

Datalogic. 2004. Study Guide: Reading between the lines. Datalogic 2004. Available from: http://www.datalogicscanning.com.html (accessed 25 April 2010).

Datalogic. 2009. Pharmaceutical distributor solves communication breakdown with barcodes. Datalogic Scanning. Available from: http://www.datalogicscanning.com.html (accessed 28 April 2010).

Dos Santos, M.A.O. 2010. Benefits derived by a major South African retailer through collaboration and innovation within its supply chain. Journal of Transport and Supply Chain Management. 41(1):102-19.

Dennison, A. 2010. Apparel retailer saves \$154 000 in store transfer cost. Avery Dennison Printer Systems Division, \#10:3.

Erasmus, M. 2002. Business intelligence: issues for management. South African Journal for Information Technology. 4(4):1-14.

Frome, J. 2010. Supply chain predictions: what's in store for 2011? SPS Commerce. 14:4.

Hum, E. \& Marciano, R. 2010. Supply chain perspective: the retail supply chain network of the future. Supply Chain Digest. 7 December 2010.

Joshi, G. 2009. Information Technology for Retail. India. Oxford University Press.

King, D. 2010. Designing retail merchandising displays: sell more, lose less. Available from: http://www.retailsolutionsonline.com.html (accessed 19 July 2010).

Mercier, P., Sirkin, H. \& Bratton, J. 2009. 8 ways to boost supply chain agility. Supply Chain Management Review. Jan/Feb 14(1):18-25.

Moore, B. 2009. Barcodes: The Next Generation. Material Handling Management. Mar 64(3):48-49.

National Academies. 2005. Advancing knowledge and the knowledge economy. Available from: http://www.advancingknowledge.com.html (accessed 11 January 2005.

Nielsen. 2011. Food Retail listings. Available from: http://cn.en.acnielsen.com/profile/ index.php?landid=6/html (accessed 12 March 2011). 
Phillips, D. 2009. Eliminate 7 wastes from your supply chain with real-time asset management solutions. Zebra Enterprise Solutions. Zebra Technologies.

Reese, A.K. 2010. Whither RFID? Supply and Demand Chain Executive. Aug/Sep 11(3):5-12.

Urban, B. \& Mangisi, E. 2008. Enterprise resource planning system implementation: investigating the process of change in medium size firms. Journal of Contemporary Management. 5:223-37.

Walker, G.J. 2009. What you scan is what you get. Material Handling Management. Aug 64(8):29-30.

Walker, K. 2010. Does your supply chain management system deliver the goods? A case study. Supply Chain Forum: International Journal. 11(2):86-89.

Yu, C. 2005. Causes influencing the effectiveness of the post-implementation ERP system. Industrial Management and Data Systems. 105(1):115-32.

Table of acronyms

\begin{tabular}{|l|l|}
\hline AIS & Automatic Identification Systems \\
\hline APS & Advanced Planning System \\
\hline CPFR & Collaborative Planning, Forecasting and Replenishment \\
\hline CRM & Customer Relationship Management \\
\hline EDI & Electronic Data Exchange \\
\hline ERP & Enterprise Resource Planning \\
\hline JIT & Just In Time \\
\hline MICR & Magnetic Ink Character Recognition \\
\hline MRP & Materials Requirements Planning \\
\hline MRPII & Manufacture Resource Planning \\
\hline POS & Point of Sale \\
\hline RFID & Radio Frequency Identification \\
\hline RSS & Reduced Space Symbology \\
\hline SCM & Supply Chain Management \\
\hline SRM & Supplier Relationship Management \\
\hline TOC & Theory of Constraints \\
\hline UPC & Universal Product Code \\
\hline WMS & Warehouse Management System \\
\hline
\end{tabular}

